\title{
Inadequate Prosthetic Rehabilitation Caused by Fibrous and Bone Hyperplasia of Maxilla - Case Report
}

\author{
Bojan Gačić, Ljiljana Stojčev-Stajčić, Ana Djinić, Milena Kalanović, Branislav Ilić, Kristina Rebić \\ University of Belgrade, Faculty of Dental Medicine, Clinic of Oral Surgery, Belgrade, Serbia
}

\begin{abstract}
SUMMARY
Normal bone healing after tooth extraction includes the following steps: blood clot forming, granulation, bone forming and final bone reorganization. In clinical settings connective tissue infiltration of extraction socket can result in fibrous scar formation rather than bone healing. Local and systemic factors seem to be major contributors to the occurrence of erratic socket healing. The aim of this case report was to describe oral-surgery treatment of a patient with inadequate bone and soft supportive tissue for prosthetic rehabilitation. Surgical procedure and recovery are presented, including final complete denture rehabilitation.

Keywords: fibrous hyperplasia; bone hyperplasia; compromised post-extraction healing; inadequate prosthetic rehabilitation
\end{abstract}

\section{INTRODUCTION}

Numerous experimental and clinical studies have investigated healing mechanisms of extraction socket. After tooth removal rapid establishment of blood coagulum occurs, followed by clot replacement with granulation tissue, osteoid and subsequently mature lamellar bone $[1,2]$. In addition, other changes of extraction site develop during the first year after tooth extraction [3]. Less traumatic surgical approach, crown and root separation as well as meticulous wound debridement with removal of all granulation tissue are advised after tooth extraction in order to provide optimal conditions for bone healing during 12 weeks and final implant placement [4]. Nevertheless, in clinical settings connective tissue infiltration of extraction socket can occur resulting in fibrous scar formation rather than bone healing. Local and systemic factors seem to be major contributors to the occurrence of erratic socket healing [5]. More recent reports indicate that implant periapical lesions are triggered by remaining scar or granulomatous tissue at the recipient site as well as endodontic pathology of extracted tooth. Obviously optimal extraction socket healing is not always achieved $[6,7,8]$.

On the other hand, inadequate dentures can cause a wide range of lesions in oral mucosa that could be prevented with follow-up and instructions how to maintain oral tissues healthy [9]. It has also been shown that complete denture wearers are more prone to pseudomembranous candidiasis, fibrous hyperplasia and stomatitis [10].

The aim of this study was to present surgical procedure of removing fibrous scar from post-extraction alveoli, which was the main complication to retention and stabilization of maxillary denture.

\section{CASE REPORT}

A 46-year-old female patient was referred to the Clinic of Oral Surgery by a prosthodontic specialist due to the patient's complaint about poor retention and stability of maxillary complete denture. An oral surgery specialist performed clinical examination during the first visit. Uneven lateral segments of maxilla were revealed along with incorrect inter-jaw relationship due to soft tissue hyperplasia in the region of maxillary tuberoses (Figure 1). Orthopan tomography analysis showed bone hypertrophy in both maxillary tuberoses. Oral surgery procedure was recommended and scheduled.

Surgical procedure was performed in the second visit under local anesthesia using 4\% Articaine hydrochloride with epinephrine hydrochloride $0.01 \mathrm{mg} / \mathrm{ml}$ (Septanest 1:100000, 4\%). Elliptical incision was made bileterally and hypertrophic fibrous tissue was removed (Figure 2). Then after, alveolar osteoplasty of the posterior maxillary regions was performed (Figure 3). According to the orthopan tomography, an exposure of sinus membrane on the left side was expected following bone removal. Diamond burs were used in order to prevent sinus membrane damage. The Schneiderian membrane was pushed caudally following the exposure (Figure 4). After hypertrophic bone removal, sutures were placed. There was no sinus membrane exposure on the right side, therefore sutures were placed imediately after bone removal (Figure 5). In the anterior maxillary region hypertrophic mucosa was removed (labium duplex), and frenectomy was performed (Figure 6). Penicillin 0,5 g three times a day, during the five days (Amoxicillin ${ }^{\circ}$, Galenika, Belgrade, Serbia) was prescribed after the surgery. The patient was discharged from the hospital the same day with a dietetic-hygienic 


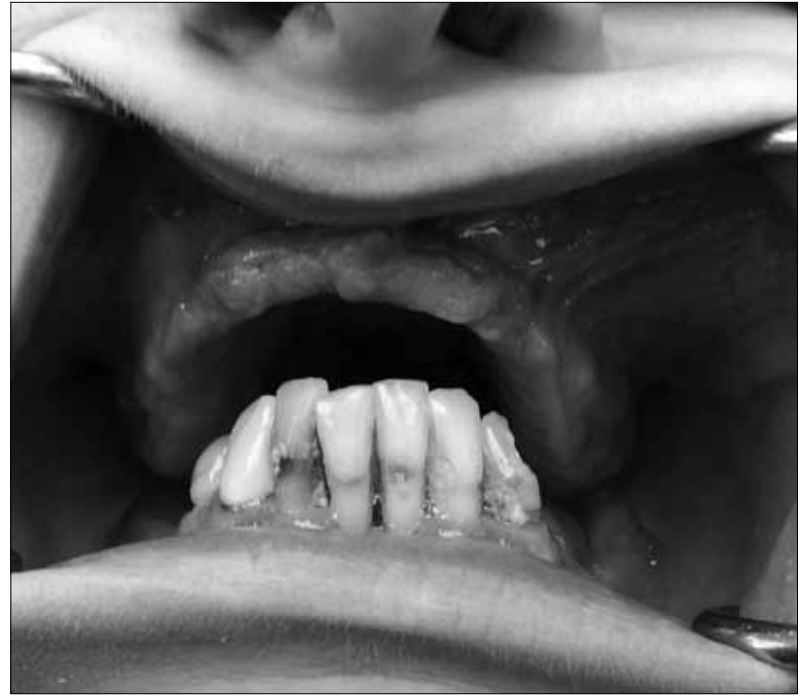

Figure 1. Preoperative situation in patient's mouth Slika 1. Preoperaciono stanje u ustima pacijentkinje

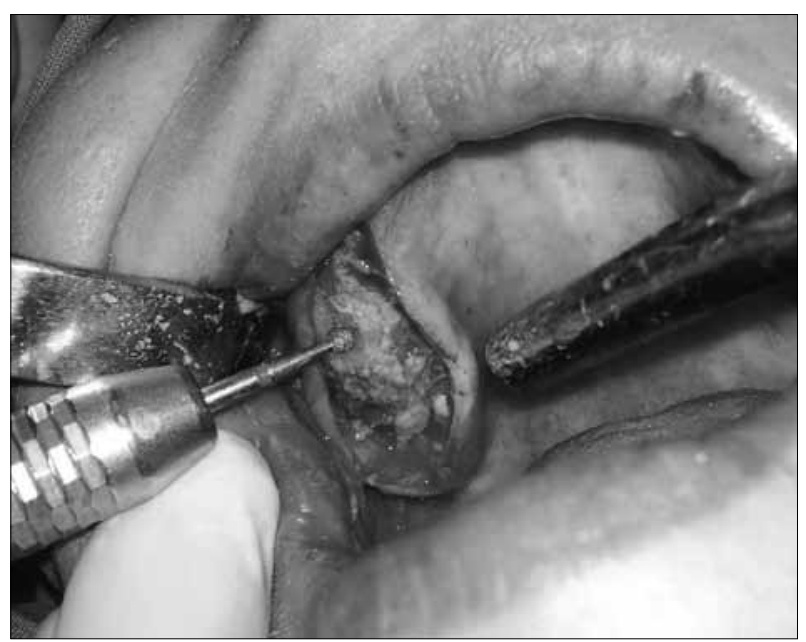

Figure 3. Alveolar osteoplasty of posterior maxillary region (left side) using a diamond bur

Slika 3. Uklanjanje koštanog tkiva dijamantskim borerom u gornjoj vilici s leve strane

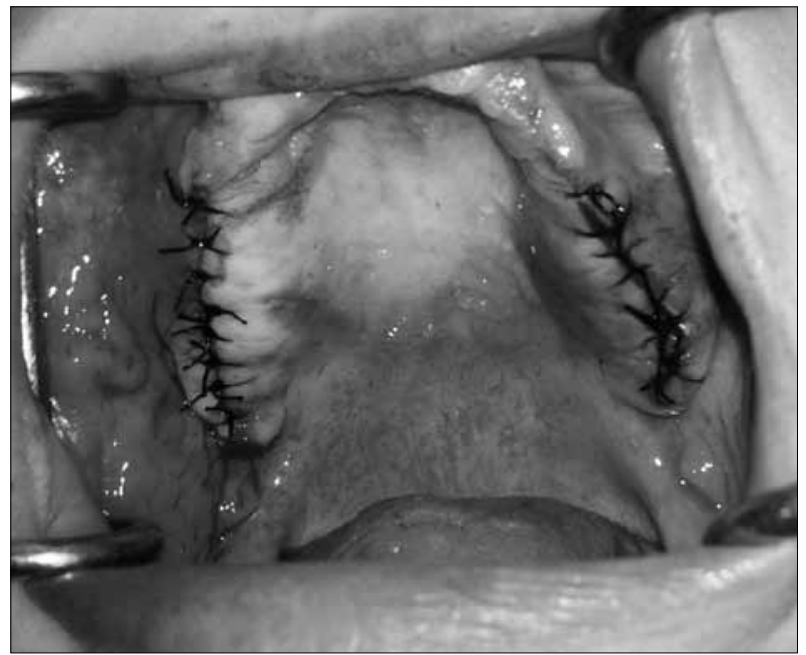

Figure 5. Surgical sutures placed in the posterior part of maxilla Slika 5. Primarno ušivene rane u bočnim segmentima gornje vilice

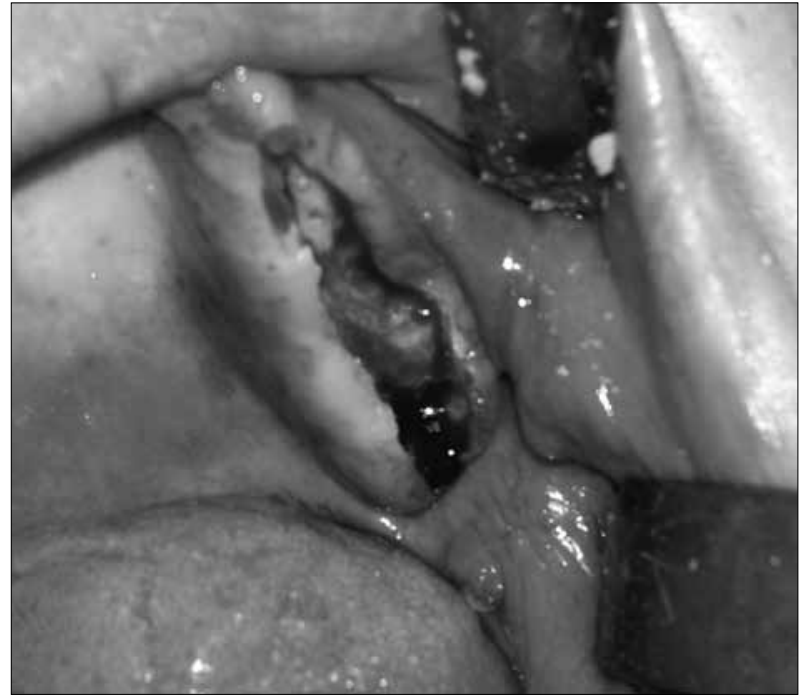

Figure 2. Elliptical incision on the left side of maxilla Slika 2. Elipsasta incizija u gornjoj vilici s leve strane

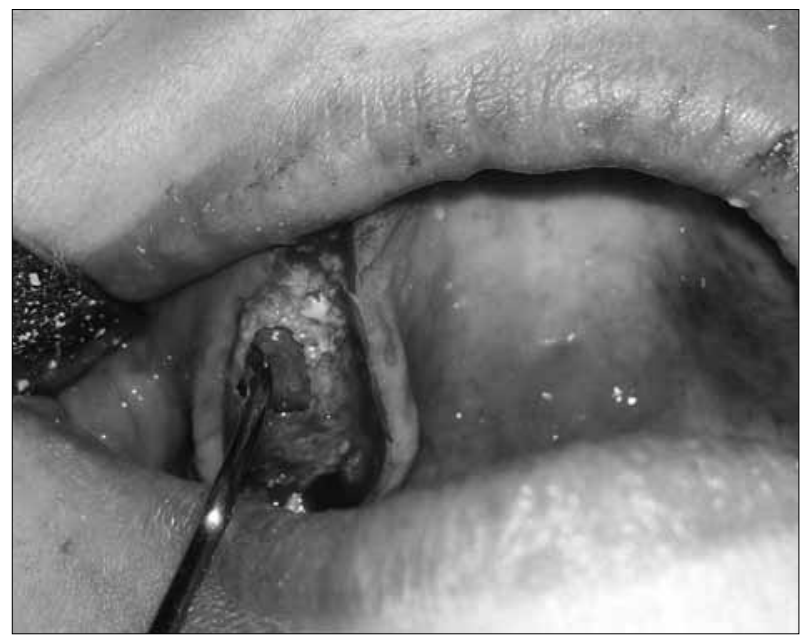

Figure 4. Schneiderian membrane pushing caudally on the left side of maxilla

Slika 4. Potiskivanje sluzokože levog maksilarnog sinusa kaudalno

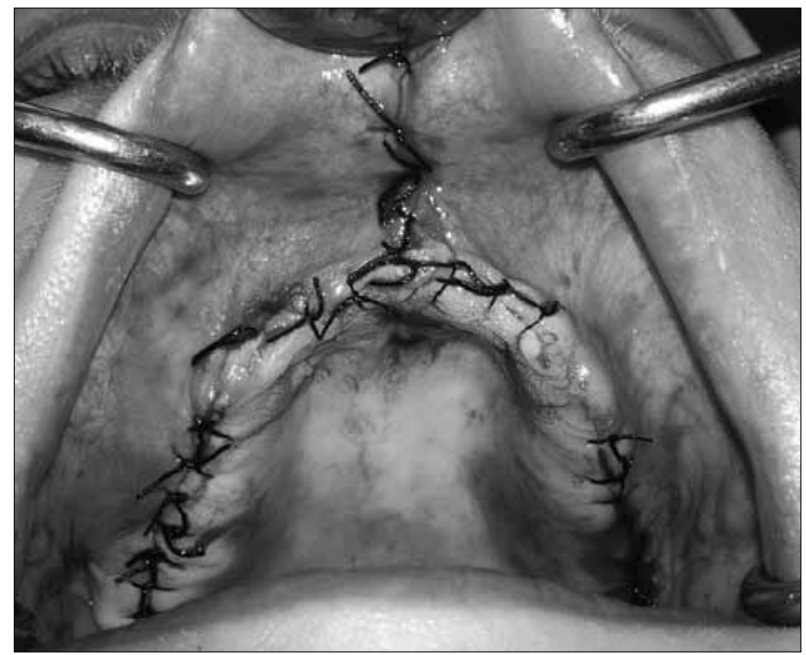

Figure 6. Surgical sutures placed in the frontal part of maxilla Slika 6. Primarno ušivene rane $u$ frontalnoj regiji gornje vilice 


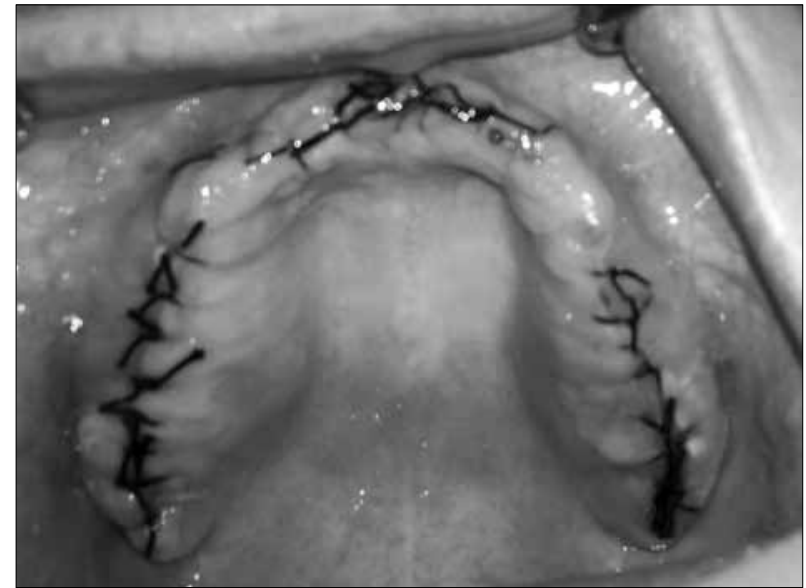

Figure 7. First postoperative day-local conditions Slika 7. Stanje u ustima pacijentkinje prvog dana nakon zahvata

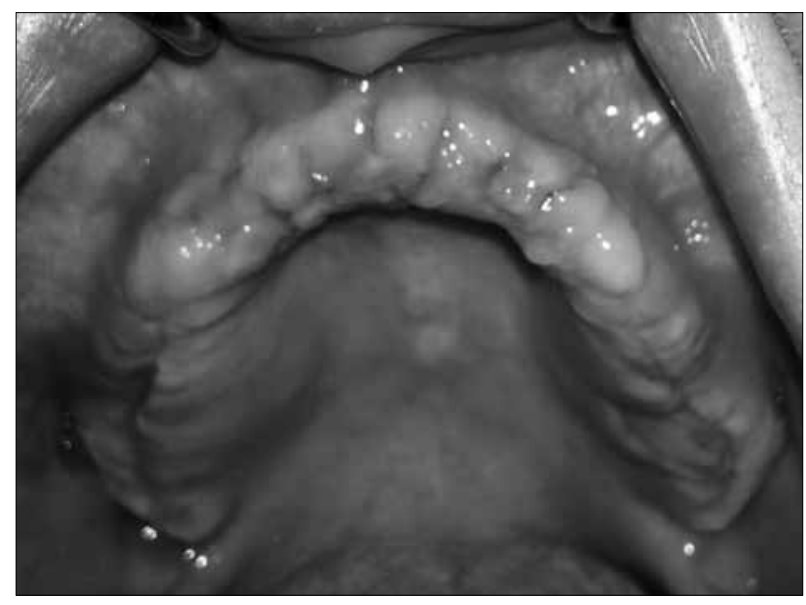

Figure 9. Seventh postoperative day - sutures removed Slika 9. Stanje u ustima pacijentkinje nakon uklanjanja konaca sedmi postoperacioni dan

regime recommendation. The follow-up examination was scheduled for one day after.

During the third visit the first postoperative examination was performed. Local postoperative conditions were normal (Figure 7). The wound was rinsed with sterile saline and patient was discharged with scheduled visit two days after.

At the fourth visit, the surgical wound showed signs of healing and local conditions were within normal limits (Figure 8).

Seven days post-surgery sutures were removed. The wound healed with primary intention (Figure 9). The next follow-up examination was scheduled for one month after the surgery, following the prosthetic rehabilitation.

On the sixth visit, one month post-surgically, the patient had complete dentures (Figure 10). Intraoral examination showed good postoperative condition including optimal stability and retention of complete dentures (Figure 11).

\section{DISCUSSION}

Many authors have investigated biological processes involved in healing process of extraction socket. An ani-

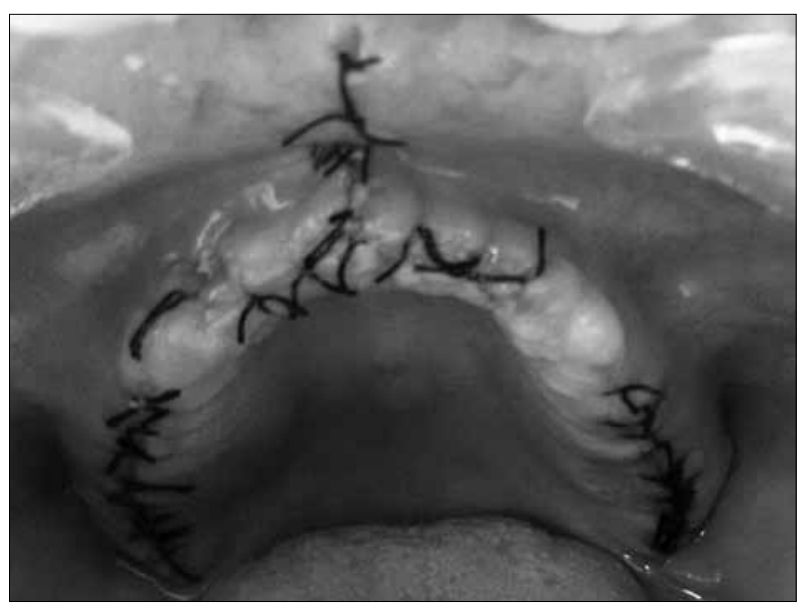

Figure 8. Third postoperative day- local conditions

Slika 8. Stanje u ustima pacijentkinje trećeg dana nakon zahvata

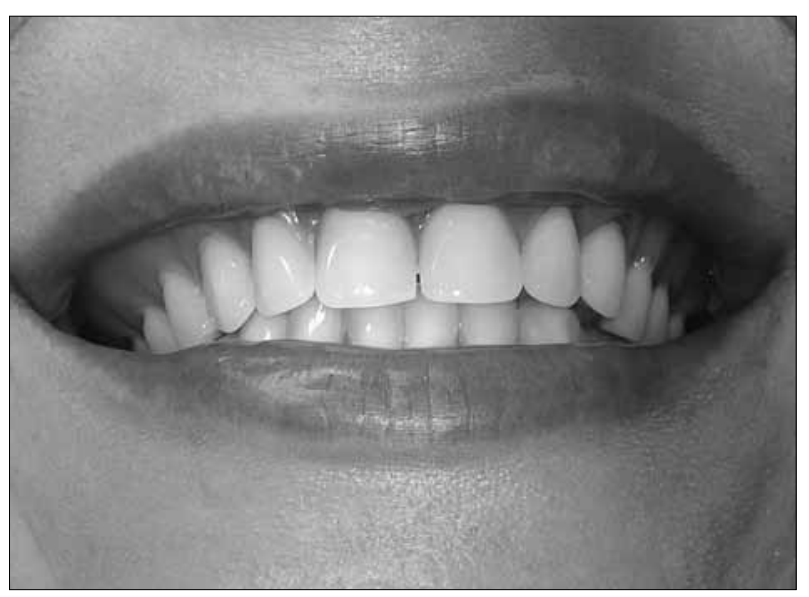

Figure 10. Complete denture rehabilitation - one month after surgery Slika 10. Stanje u ustima pacijentkinje nakon protetičke rehabilitacije mesec dana od operacije

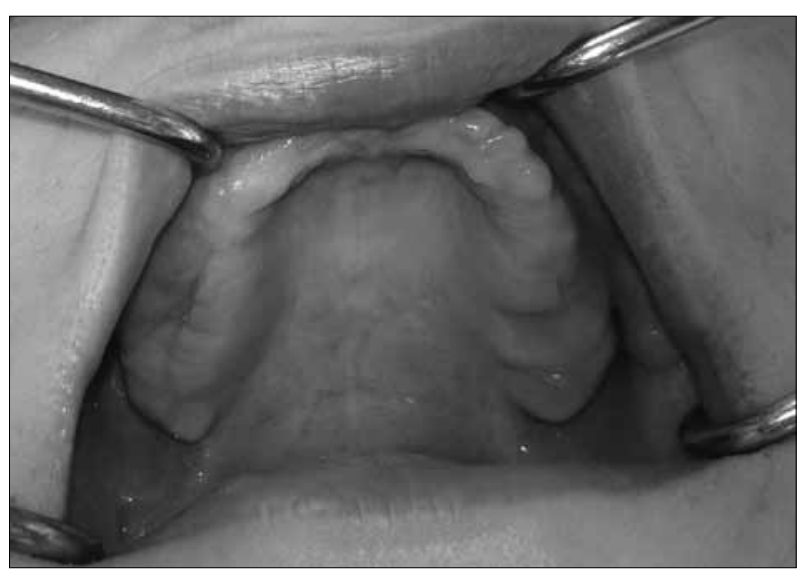

Figure 11. Soft tissue - one month after surgery

Slika 11. Stanje mekih tkiva mesec dana nakon operacije

mal study demonstrated that extraction socket healing involved a series of events including formation of a coagulum replaced by provisional connective tissue matrix first, and then by a woven bone while finally by a lamellar bone and bone marrow. Furthermore, in the process of healing, a hard tissue bridge is formed, i.e. cortical bone, which "closes" the socket [2]. Extraction socket healing in humans includes similar phases with major changes 
during the first year post-extraction and 50\% reduction of alveolar ridge width during that period $[1,2,3]$. After monitoring healing process of extraction sockets during a 6-month period it was shown that provisional connective tissue has been consistently formed within the first weeks of healing, while the interval during which mineralized bone is laid down was less predictable [11]. Another study showed that approximately $5 \%$ of extraction sites featured erratic extraction socket healing. In this study, the term erratic healing was defined as healing of extraction sockets that resulted in soft tissue infiltration, most likely fibrous scar tissue, rather than bone formation even after meticulous debridement and healing interval that exceeded 12 weeks. The most unpredictable sites were sites where preexisting periodontal, endodontic, or combined periodontal-endodontic pathology was present. Erratic healing was more likely to occur in younger patients and patients with high blood pressure. Other systemic factors, such as gender, diabetes and smoking did not show positive correlation with erratic socket healing [5].

The patient described in the current study was in good general medical condition, however she had a history of chronic periodontal disease that progressed to terminal phase and caused multiple teeth extraction. Severe periodontal pathology may be the explanation for connective tissue infiltration and fibrous scar formation following teeth removal in this patient. Even though meticulous curettage of extraction socket is performed after tooth removal, an optimal bone healing might not occur. The surgeon should be prepared to deal with consequences of irregular healing in order to provide the patient a possibility for implant placement or prosthetic rehabilitation.

\section{ACKNOWLEDGMENT}

The authors acknowledge support of the Ministry of Education, Science and Technological Development of the Republic of Serbia, grant III41007.

\section{REFERENCES}

1. Amler MH. The time sequence of tissue regeneration in human extraction wounds. Oral Surg Oral Med Oral Pathol. 1969; 27:309-18.

2. Cardaropoli G, Araujo M, Lindhe J. Dynamics of bone tissue formation in tooth extraction sites - an experimental study in dogs. J Clin Periodontol. 2003; 30:809-18.

3. Schropp L, Wenzel A, Kostopoulos L, Karring T. Bone healing and soft tissue contour changes following single-tooth extraction: a clinical and radiographic 12-month prospective study. Int J Periodontics Restorative Dent. 2003; 23:313-23.

4. Hammerle CHF, Chen ST, Wilson TG. Consensus statements and recommended clinical procedures regarding the placement of implants in extraction sockets. Int J Oral Maxillofac Implants. 2004; 19:26-8.

5. Kim JH, Susin C, Min JH, Suh HY, Sang EJ, Ku Y, et al. Extraction sockets: erratic healing impeding factors. J Clin Periodontology. 2014; 41:80-5.

6. Quirynen M, Vogels R, Alsaadi G, Naert I, Jacobs R, van Steenberghe D. Predisposing conditions for retrograde peri-implantitis, and treatment suggestions. Clin Oral Implants Res. 2005; 16:599-608.

7. Romanos GE, Froum S, Costa-Martins S, Meitner S, Tarnow DP. Implant periapical lesions: etiology and treatment options. J Oral Implantol. 2011; 37:53-64.

8. Lefever D, Van Assche N, Temmerman A, Teughels W, Quirynen M. Aetiology, microbiology and therapy of periapical lesions around oral implants: a retrospective analysis. J Clin Periodontol. 2013; 40:296-302.

9. Coelho CMP, Sousa Y, Dare AMZ. Denture-related oral mucosal lesions in a Brazilian school of dentistry. J Oral Rehabil. 2004; 31:135-9.

10. Vallejo M, Diaz-Canel AIM, Martin JMG, Garcia MG. Risk factors for oral soft tissue lesions in an adult Spanish population. Community Dent Oral Epidemiol. 2002; 30:277-85.

11. Trombelli L, Farina R, Marzola A, Bozzi L, Liljenberg B, Lindhe J. Modeling and remodeling of human extraction sockets. I Clin Periodontol. 2008; 35:630-9.

Received: 29/12/2014 • Accepted: 20/02/2015 


\title{
Ugrožena protetička rehabilitacija usled fibrozne i koštane hiperplazije gornje vilice - prikaz pacijenta
}

\author{
Bojan Gačić, Ljiljana Stojčev-Stajčić, Ana Đinić, Milena Kalanović, Branislav Ilić, Kristina Rebić \\ Univerzitet u Beogradu, Stomatološki fakultet, Klinika za oralnu hirurgiju, Beograd, Srbija
}

\begin{abstract}
KRATAK SADRŽAJ
Nakon vađenja zuba obično slede brza organizacija koaguluma, formiranje granulacionog tkiva, osteoida, a zatim i zrele lamelarne kosti. Međutim, klinički se neretko može sresti infiltracija ekstrakcione alveole vezivnim tkivom, uz stvaranje fibroznog ožiljka umesto novostvoren kosti. Za to su odgovorni brojni lokalni i sistemski faktori koji doprinose nepravilnom zarastanju ekstrakcione alveole. Cilj ovog rada je bio da se opiše oralnohirurško lečenje pacijenta s neodgovarajućim stanjem koštanog i mekog nosećeg tkiva gornje totalne proteze. Prikazani su hirurški postupak i postoperacioni tok, zaključno s konačnim odgovarajućim protetičkim zbrinjavanjem pacijenta, koji je doveo do pravilnog zarastanja rane i time zadovoljavajuće protetičke rehabilitacije.

Ključne reči: fibrozna hiperplazija; koštana hiperplazija; kompromitovano postekstrakciono zarastanje; neodgovarajuća protetička rehabilitacija
\end{abstract}

\section{UVOD}

Brojne eksperimentalne i kliničke studije su ispitivale zarastanje ekstrakcionih alveola. Pokazano je da nakon vađenja zuba slede brza organizacija koaguluma, stvaranje granulacionog tkiva, osteoida, a kasnije i zrele lamelarne kosti [1,2]. Klinički je utvrđeno da područje ekstrakcije zuba podleže najvećim promenama tokom prvih godinu dana [3]. Prilikom planiranja ugradnje implantata nakon ekstrakcije, savetuju se atraumatski hirurški rad, separacija zuba i korenova, kao i pažljiv debridman rane uz uklanjanje inflamiranog granulacionog tkiva, kako bi se obezbedili uslovi za neometano zarastanje kosti tokom prvih 12 nedelja oporavka [4]. Međutim, klinički se neretko može sresti infiltracija ekstrakcione alveole vezivnim tkivom, uz formiranje fibroznog ožiljka umesto novostvorene kosti. Lokalni i sistemski faktori, čini se, doprinose javljanju nepravilnog zarastanja ekstrakcione alveole [5]. Novija istraživanja takođe pokazuju da su implantatne periapikalne lezije posledica zaostalog ožiljnog ili granulomatoznog tkiva u regiji implantacije, kao i endodontske patologije ekstrahovanog zuba; stoga se optimalno koštano zarastanje alveole ne dešava uvek $[6,7,8]$.

S druge strane, neodgovarajuće protetičke nadoknade mogu uzrokovati nastanak brojnih lezija oralne sluzokože, što se može sprečiti redovnim kontrolama radi očuvanja zdravlja oralne mukoze [9]. Ranije istraživanje je pokazalo da nošenje totalnih zubnih proteza povećava incidenciju nastanka pseudomembranozne kandidijaze, fibrozne hiperplazije i stomatitisa [10].

Cilj ovog rada je bio da se predstavi hirurški postupak uklanjanja fibroznog ožiljka iz postekstrakcione alveole koji je bio osnovna smetnja retenciji i stabilizaciji gornje totalne proteze.

\section{PRIKAZ PACIJENTA}

Žena stara 46 godina došla je na Kliniku za oralnu hirurgiju Stomatološkog fakulteta u Beogradu, prema uputu specijaliste stomatološke protetike zbog nemogućnosti nošenja gornje totalne zubne proteze. Tokom prve posete urađen je klinički pregled i dijagnostikovano da je bočni segment leve i desne gornje vilice izmenjen, te da su međuvilično odnosi poremećeni zbog fibrozne hiperplazije gingive u regiji tubera maksile (Slika 1). Analizom ortopantomografskog (OPT) snimka dijagnostikova- na je koštana hipertrofija maksilarnog tubera obostrano. Nakon pregleda i analize rendgenskog snimka pacijentkinji je zakazana hirurška intervencija.

Tokom druge posete obavljen je hirurški zahvat korekcije mekih i koštanog tkiva gornje vilice. Nakon primene $8 \mathrm{ml}$ lokalnog anestetičkog rastvora četvoroprocentnog artikaina s adrenalinom (Septanest 1:100.000,4\%), učinjena je bilateralna elipsasta incizija, a potom uklonjeno hipertrofično fibrozno tkivo (Slika 2). Zatim je izvršena osteoplastika bočnih segmenata leve i desne maksile (Slika 3). Prilikom uklanjanja koštanog tkiva bilo je očekivano, na osnovu analize OPT snimka, da će se s leve strane eksponirati sluzokoža maksilarnog sinusa. Zbog toga su korišćeni dijamantski boreri, kako bi Šnajderova membrana ostala netaknuta. Nakon ekspozicije membrana je potisnuta kaudalno (Slika 4). Potom je uklonjen ostatak hipertrofičnog koštanog tkiva i rana primarno ušivena. Sa desne strane sluzokoža maksilarnog sinusa nije bila eksponirana, tako da je nakon uklanjanja hipertrofičnog koštanog tkiva rana primarno ušivena (Slika 5). U frontalnoj regiji gornje vilice uklonjena je hipertrofična mukoza (labium duplex), koja je nastala kao posledica nošenja neodgovarajuće totalne proteze, a potom je izvršena frenektomija i uklonjen frenulum labii oris superioris. Rane su primarno ušivene (Slika 6). Nakon hirurške intervencije pacijentkinji je prepisana antibiotska terapija - penicilin u dozi od $0,5 \mathrm{~g}$ na osam sati $\mathrm{u}$ trajanju od pet dana (Amoksicilin ${ }^{\circledR}$, Galenika, Beograd, Srbija), i preporučen higijensko-dijetetski režim, nakon čega je puštena kući. Kontrolni pregled je zakazan za 24 sata.

Tokom treće posete obavljena je prva postoperaciona kontrola. Lokalni nalaz je bio normalan (Slika 7). Rana je isprana fiziološkim rastvorom. Pacijentkinji je naredna kontrola zakazana za dva dana.

Tokom četvrte posete, trećeg dana od hirurškog zahvata, postoperacioni tok je bio normalan, a hirurška rana u primarnom zarastanju isprana je fiziološkim rastvorom (Slika 8). Sledeća kontrola je zakazana sedmog postoperacionog dana.

Nakon sedam dana od hirurške intervencije uklonjeni su konci i izvršena je toaleta rane. Lokalni nalaz je bio normalan, rana je primarno zarasla (Slika 9) i pacijentkinja je puštena kući. Naredna kontrola zakazana je za mesec dana, po izradi protetičkih nadoknada.

Tokom šeste posete, mesec dana nakon hirurške intervencije, pacijentkinja je došla na kontrolni pregled s izrađenim novim 
protetičkim nadoknadama (Slika 10). Intraoralnim pregledom utvrđeno je da su rane potpuno zarasle, kao i da su zubne nadoknade u ustima stabilne (Slika 11).

\section{DISKUSIJA}

Brojna istraživanja su se bavila ispitivanjem bioloških procesa uključenih u zarastanje ekstrakcionih alveola. Studija na životinjskom modelu je pokazala da zarastanje ekstrakcione alveole podrazumeva niz događaja, uključujući zamenu stvorenog koaguluma provizornim vezivno-tkivnim matriksom, potom nezrelim i, konačno, zrelim koštanim tkivom i koštanom srži. Uz to, tokom zarastanja se formira i čvrst most od kortikalne kosti koji „zatvara" alveolu [2]. Postekstrakciono zarastanje kod ljudi prolazi kroz slične faze, pri čemu se najveće promene dešavaju tokom prvih godinu dana, kad se i za 50\% redukuje širina alveolarnog grebena $[1,2,3]$. Cilj jednog od kliničkih istraživanja bilo je šestomesečno praćenje zarastanja ekstrakcionih alveola. Rezultati su pokazali da se privremeno vezivno tkivo pouzdano formira tokom prvih nedelja zarastanja, a da je teže predvideti interval tokom kojeg se stvara mineralizovano koštano tkivo [11]. Međutim, rezultati nedavno objavljene studije pokazuju da se na približno $5 \%$ područja ekstrakcija zuba javilo nepravilno zarastanje. U pomenutom istraživanju je nepravilno zarastanje definisano kao infiltracija postekstrakcione alveole mekim, po svoj prilici, ožiljnim vezivnim tkivom, pre nego novostvorenom kosti, uprkos temeljnom debridmanu rane i periodu zarastanja dužem od 12 sedmica. Najveći broj regija nepravilnog zarastanja bio je posledica parodontalne ili endodontalne patologije ekstrahovanih zuba, kao i udruženih endoparodontalnih lezija. Nepravilno zarastanje je bilo verovatnije kod mlađih pacijenata, kao i osoba s hipertenzijom. Drugi sistemski faktori, poput pola, dijabetesa i pušenja, nisu bili u pozitivnoj korelaciji s nepravilnim zarastanjem alveole [5].

Naša pacijentkinja je bila dobrog opšteg zdravlja, međutim, imala je hroničnu parodontopatiju koja je napredovala do terminalnog stadijuma, te su stoga bile indikovane multiple ekstrakcije zuba. U ovom slučaju bi teška parodontalna patologija mogla biti objašnjenje za vezivno-tkivnu infiltraciju i ožiljno zarastanje alveola nakon vađenja zuba. Uprkos temeljnoj kiretaži ekstrakcione alveole nakon vađenja zuba, postoji mogućnost da se željeno koštano zarastanje ne dogodi. Hirurg bi trebalo da bude spreman da se suoči s posledicama ovakvog nepravilnog zarastanja, kako bi pacijentu omogućio ugradnju implantata ili neki drugi vid protetičke rehabilitacije.

\section{ZAHVALNICA}

Autori zahvaljuju Ministarstvu prosvete, nauke i tehnološkog razvoja Republike Srbije na podršci u realizovanju rada u okviru projekta broj III41007. 